\title{
Interview
}

\section{Using marketing analytics to drive innovation - An interview with Trae Clevenger of Targetbase}

\section{Trae Clevenger}

leads Targetbase's innovation efforts, focusing on analytics and technology. He has been a key contributor to the marketing services provider's number one ranking in analytics in the last two Forrester Waves. Trae has delivered measurable results across multiple industries, for Fortune 500 companies, for $15+$ years.

ABSTRACT Marketing analytics has moved beyond traditional campaign response and customer relationship management (CRM). Driving improved, sustainable results requires that marketers understand and optimize consumer engagement in a more complex, social environment where the customer dictates the relationship. Michael Moon interviews Trae Clevenger of Targetbase about innovations in the field.

Journal of Digital Asset Management (2009) 5, 216-236. doi:10.1057/dam.2009.13

Keywords: statistical analysis; predictive analytics; segmentation; optimization; web analytics; relationship marketing

MM: We're here with Trae Clevenger of Targetbase. Trae, would you describe your current position and a few career highlights? TC: My name is Trae Clevenger, and I'm currently VP of Strategy and Innovation at Targetbase. We are a database, digital and direct marketing agency.

My role at Targetbase is focused on innovation - helping to drive innovation across clients, particularly in the areas of analytics and digital marketing. But, given that Targetbase is an integrated marketing agency focused on outcomes, most of our approaches and innovation also impact technology and creative.

In terms of my personal background, I have worked across multiple industries, and with many Fortune 500 companies, in strategy, analytics and solution delivery. My areas of expertise include statistical analysis and modeling, predictive analytics, segmentation, optimization, web analytics, relationship marketing, engagement analytics and behavioral targeting.

I do have a very analytics-heavy background, but with a particular focus in recent years on strategy, utilizing insight I've gained from my analytics research to drive better outcomes. MM: How would you describe Targetbase, its typical clients and solutions?

TC: Targetbase was founded in 1979 as a spinoff of MARC Research. That foundation in analytics has remained at the core of everything we have done throughout the years, so much so that from a business model standpoint, analytics and insight are the hub. The spokes coming off that are output and outcomefocused.

So, technology - creative - strategy - all coming out of what we hope and believe is superior consumer insight. Insight that combines behaviors and attitudes.

Our clients are global, including several Fortune 500 companies. Major client industries include travel, hospitality, finance, insurance, pharma, health care, automotive, utilities, packaged goods and retail. One of the unique things about Targetbase, as an agency, is the length of our client relationships.

Concerning solutions, we provide strategy, analytics, technology and creative. However, 
the real differentiator is how all of those pieces come together to provide superior solutions for our clients. For example, technology and analytics combine to produce more actionable business intelligence. Creative and technology combine to produce dynamic, customized content delivery. Analytics and creative combine to produce communication planning and more targeted, impactful content.

Our tag line is 'Database. Digital. Direct.' So much of what we're doing these days is increasingly in the digital space and the online world, incorporating not just web, but mobile and every other consumer touchpoint. We strive to achieve a 360-degree view of the consumer.

MM: Would you just walk us through one or two case studies?

TC: Yes. Probably one of the areas that Targetbase is most well known for is in consumer segmentation or cohorting.

MM: Would you give us a quick little primer on cohorting?

TC: Certainly.

If you look at our packaged goods clients, they have tremendous portfolios of brands.

One client came to us many years ago with the question of how they could leverage consumer insight, and gain a better understanding of their consumer in order to know what mix of brands to be promoting or offering to each person on their database.

This is very much turning the old model of brand marketing on its head. It's not about the brand - it's about the consumer.

You find more often than not - especially among large portfolios of brands - that there are natural groupings or segments of consumers. What we refer to oftentimes as a 'cohort.' A cohort is a group of consumers that tend to utilize a group of brands or a mix of brands in a particular way.

We developed a methodology and approach to identifying those unique segments or cohorts within their consumer base. We identified them in such a way that the client could know not only who the consumers are from a behavioral and attitudinal standpoint, but then what products they were likely to be interested in. The desired result is to drive relevant messaging and offers to optimize their brands at the individual consumer level.
MM: Perhaps in your definition of cohorts, you and your clients use naming conventions? TC: Yes. Absolutely.

There are certainly broad conventions. But one of the services that we offer our clients is a truly customized approach to segmentation and cohorting, specific to their brands and customers. There are unique differences.

There are certainly themes that crop up on a regular basis, but it is actually a customized approach - as opposed to, say, the traditional prism cluster type of approach where every neighborhood in the United States is dubbed a particular name, to fit within that prism cluster.

When we talk cohorts, it's in the context of a particular brand or group of brands.

MM: If I understand that right, Trae, traditional consumer-segmentation efforts use the census, credit histories and other forms of household data? That might entail the use of PRISM data, creating a cluster of what is basically a neighborhood. That entails the pre-supposition that everyone in that neighborhood will buy a similar set of things; that consumers that share similar socio-economic backgrounds and motivations will purchase similar products, correct?

TC: Yes. That's correct.

MM: However, in reality, each household of a particular neighborhood often represents a huge divergence or difference of consumer appetites, criteria and mind-styles. So the idea of 'cohorting' takes another approach: rather than working from the physical data (households of a neighborhood) to develop a data set, you now work backwards consumer appetites, criteria and mind-styles, creating logical set that you call a cohort. This approach of cohorts or logical groupings of buyers makes neighborhoods like Swiss cheese - where each hole represents a distinct set of buying criteria and, when group together, create a cohort. TC: Absolutely.

We are incorporating attitudinal data and demographic data and behavioral data. So there are certainly differences within neighborhoods along attitudinal and behavioral lines.

A lot of it has to do with the methodology we employ. Oftentimes, for example, beginning with broad, syndicated data like a Simmons or an MRI, that allows us to incorporate many 
of those things. Not just geographic, demographic data, but attitudes and behaviors across a broad swath of areas including brand usage.

Oftentimes we'll start with syndicated data like that. Other times, where available, we'll start with a consumer's database. If they have an existing database of their consumers, mapping them into syndicated data or third-party data or direct primary research.

One of the things, by the way, since we're talking about Targetbase and our approach one of the things that we talk a lot about, and actually promote as a point of differentiation, is that we are data-agnostic. By that, we mean that we're not trying to sell data. That's not part of what we provide - if for no other reason because we don't want the results and outcomes to be biased.

So if one particular vendor is providing appended data that we can use for our clients great! We'll take it. If, on the other hand, we need to go out with primary research to capture that information ourselves, that's fine, too.

It's about the solution that we're trying to deliver. Not about selling data.

MM: As you said, you can take one way of looking at the data in standard cluster analysis, using data from syndicated research or compiled data. Or you can segment along themes that reflect the mindset of various cohorts. Thus, segmentation themes support brand-portfolio mix optimization.

With a large portfolio of brands, segmentation themes enable you to say, 'Okay, what is the optimum mix of brands that we should market, can market, have marketed, to this particular profile of behavioral and attitudinal data?' TC: Exactly.

As I said, there are certainly themes that crop up across clients and across verticals. One example for a particular client is a segment that we have dubbed, 'Maxed Moms.' For that group - some of the themes or points that come to mind are these: they're mothers, time crunched - so their time is important to them; however, they also want to feel like they are pampering their family and taking care of their family in a very traditional sense.

So, communication to that market segment is driven by our understanding of those attitudes and behaviors - not only imagery, copy, but also cohorting analysis tells us which products the client is likely to win with for that segment.

For the Maxxed Mom, you'd want to promote products that are geared toward time-saving and/or pampering your family. Home-cooked meals in this case might resonate very well with that segment.

Then we incorporate scientific test and control methodology to determine if - in fact we can win with that particular segment, with that set of products.

MM: Let's expand on this a bit. What are the differences between how you work with a consumer packaged-goods firms where you have really a strong brand leadership, and then, with a standard marketing operation.

TC: Many times, in packaged goods, our direct client within the organization is not P\&L-responsible. So there is a good deal of internal buy-in. We are often partnered with clients that are household marketing groups. They're owners of the database and the relationship. But not necessarily the brand.

The upside is, those are often our strongest client relationships, because they are true partnerships. We're by their side helping them to prove from a return and from an ROI perspective that these programs and these strategies and approaches are in fact driving sales.

That's where we really excel because of our analytics background. It's in proving, quantitatively, the impact that marketing and relationship efforts have on actual bottom-line sales.

Now, the non-CPG - or those that are more directly responsible from a P\&L standpoint ... those relationships, in terms of how they use analytics - certainly there's less of a selling aspect. We're not so busy trying to convince the client - or the client's client - that what we're doing is worth investing in. But from a business operations standpoint, at least the clients that we've worked with, are huge proponents of not only consumer-level analytics, but - in particular - business intelligence.

For example, in our automotive experience, you've got the need to not only drive consumer relationships and drive content, but also from an insight and intelligence standpoint, to provide to them and their executive team evidence that these programs are effective. 
For lack of a better word, and I'm not a big fan of the term, but 'Dashboards' or 'reporting solutions.' BI Solutions. This lets them see the in some cases - weekly or daily impact that their marketing dollars are having.

I think generally speaking, our clients work with us in large part because of our analytics focus.

There is a little bit of a different flavor to it. I'd also add a slightly different distinction, too. You mentioned the difference between CPG and non. One other important distinction is the access to or lack of POS data.

In the case of CPG clients, most often, they don't have direct access to retailer data. If they don't have retail stores themselves, then how do they measure the impact that programs are having on sales - if you don't have sales data?

There again, I think is a recent area where Targetbase has really pioneered some truly innovative approaches - to quantitatively understand the impact of your relationship marketing efforts and your direct marketing efforts on sales. That's opposed to, say, a direct e-commerce site, where you can show on the site itself, interaction with a particular piece of content that drives sales. How do you do that when you don't have e-commerce?

MM: Could you give me an example of some of the innovations that Targetbase has brought to the CPG area? Specifically, where you've worked around the lack of POS sales data? TC: Yes. In fact, this gets specifically into what we refer to internally as our 'pattern of engagement analysis.' We actually pioneered this for a direct commerce site - a travel site. We then ported it over into a CPG environment, without the transactional data. MM: Would you expand on the strategy of first establishing a baseline pattern of engagement? Shall I assume that you first developed the data structure and approach using this very robust, high volume e-commerce site?

TC: That's where the idea started.

MM: So, the idea of patterns of engagement came out of dealing with real customers, real services. Real content. Real transactions.

TC: Exactly.

MM: Shall I assume that you developed an evolving set of analytic themes and data-analysis patterns that you then brought back into an area, where you lacked one critical part of the overall analytic equation - real POS data. As a function of the analytic themes and patterns you developed where you did have it, did you find that you could then infer what the other non-POS activity data were actually telling you?

TC: I would say yes, from a methodology standpoint. The actual patterns of engagement themselves are unique to the separate clients.

But yes in the sense that the methodology that we developed - which I'll describe in a second - we cut our teeth in a very much hands-on transactional data sort of way, in order to move that approach over to other clients.

We tend to view engagement differently, I think, than most.

When you refer to 'engagement,' or when you see it out there in the marketplace, most are talking in a very aggregated sense, and in a very point-in-time sense.

For example, I put a video on YouTube and I got 125000 people to view it over the last week. That's my engagement metric.

Well, that's not the way we think about engagement. That's one of the reasons we refer to it as a 'pattern of engagement' at Targetbase and with our clients.

The way we view this idea is that each individual - known or inferred - as they come to your site or engage with an application on their iphone, whatever the case may be, they leave clues.

For example, if somebody logs onto a foodrelated brand site. They go view their recipe box, where they've stored recipes they like. They view a video on how to make macaroni and cheese or whatever the case may be. They engage with the site.

Each of those activities is tracked. And most importantly, each of those activities is then stored on a database at the individual level. So from a processing standpoint and from a data-capture-and-storage standpoint, it is sizable. But thankfully we have the technology to achieve that, now.

As you mentioned earlier in the call, we have the analytical tools to utilize that now, as well.

But each of those activities is stored at the individual level on a database. Then our approach is to basically - in the beginning subjectively weight each of those activities. 
To categorize them in terms of their relation to our desired outcome. In this case, purchase.

For example, the fact that I open an e-mail is a much lower form of engagement than printing off a coupon, if the ultimate objective is that they're going to purchase my product.

The reason I say, 'in the beginning,' it is subjective is because much of the time we have to work with our marketing partners to just have a starting point for what we think the impact of things is going to be. Then as we capture more data, we can actually model or regress in order to determine the actual impact of interaction with a particular piece of content on the ultimate outcome of purchase.

For example, there might actually be a certain class of coupons - or a certain class of e-mails, videos or what have you - that are more predictive or have a bigger impact on the likelihood of purchase.

Once we establish that weighting paradigm then everything that every consumer does with this, that we can measure and track, is captured and stored and weighted and rolled up into this metric that we refer to as 'pattern of engagement.' It's captured over time.

For example, for some of our clients, we have three-plus years for those that have been there that long, of everyone on their database, and their pattern of engagement. In this case, we store it in monthly buckets. We roll it up into months. Then we're able to perform time-series analysis on it. That allows us to trend it and to model it.

We can then say that at the individual consumer level, 'Here's somebody who is high in terms of their level of engagement, and they're decreasing in activity from a directional standpoint.' That vector or that combination of volume and direction tells us how we need to interact with them from a relationship standpoint. 'Here's somebody who's mid-level engaged, but they're increasing in their engagement.' That again dictates how we interact with that person.

I think the uniqueness in the approach is the sophistication of the analytics, certainly, and the strategy it provides. But there is also a big technology component. Ensuring the proper tagging and tracking is in place, not to mention the sheer size of the proposition to capture all the engagements each individual consumer has with us, and to store them on a database, over time.

MM: How can you use longitudinal data about the inferred unknown individual and produce useful insights?

TC: Well, certainly from a unique identification standpoint, there are the old standby approaches, cookies, which aren't perfect. You put a cookie on someone's machine, and they can delete it. But many times, that's a very viable approach. An individual - at least the same cookie - will return to the site and engage with you over a certain period of time.

One of the things that we pioneered with one of our travel clients was the use of Bayesian Statistics. Bayesian Inference with web data.

Using a Bayesian approach as opposed to a classical statistical approach allows us to do a few things.

We can begin with subjective assumptions. To say that, 'When somebody comes to our homepage, we're going to assume that they're there to buy a ticket.'

But the approach that we then take is, everything that an individual does or doesn't do - or how long they view a particular piece of content or what have you - is used as evidence to update the probability that they're going to do what we expect them to do.

If you come to the homepage, we can know just by looking at historical data that let's say hypothetically - ten percent of the people that hit the homepage end up booking a ticket.

So when somebody hits the homepage and they're there for the first time, we say, 'Our expectation of your booking a ticket has a probability of 10 per cent.' But then that person clicks on a particular piece of content, or they go to a different section of the site, and that probability is dynamically updated.

So the approach is an ever-learning, everimproving approximation of who an individual is and what they're there to do. That's very much a foundational principle at Targetbase. That ever-improving approach.

I often use the analogy that we may start with a really grainy, fuzzy picture. But as we move forward, that picture becomes clearer and clearer. One of the things that impressed me the most in our early talks with Alterian was our like-minded philosophy. 
They were running through some slides, and they used the analogy of a 'fingerprint,' that was partially concealed. Slowly over time, it was being revealed. Of course, that analogy fits perfectly with this idea of, 'You may only know a little bit right now. So you're making an assumption with maybe relatively low confidence that it's true. But over time, you increased the confidence. You increase what you know about an individual. You increase your predictive ability in terms of what they're going to do.'

MM: Let's move beyond cookies and other kinds of unique identifiers that a user may provide. If I'm a customer and go to your site, it doesn't take more than a click or two to re-establish the fact that I'm a particular customer and link my current activity to a customer record. You've got now good longitudinal data in terms of what I'm doing and how I'm doing it.

TC: Right.

MM: What other techniques - either innovative or just standard-issue data analysis used in a new way - do you use in identifying the true identity of this inferred-unknown user? TC: Clearly, when somebody comes to the site and logs in, they're a member or they're registered. We know immediately who they are.

Maybe the next step down or a lower level would be a cookie-based approach. Then I think probably beneath that - in terms of the degree to which we know an individual, we go from trying to identify an actual 'John Smith at 1234 Main Street' to identifying individual patterns of engagement.

It's not so much about identifying an individual's name and address. That's obviously ideal. We'd love to have that level of knowledge. But when we don't, our approach at Targetbase is, 'Let's know what we can and infer the rest.'

Let's say somebody comes to the site and there's not a recognizable cookie on their machine. We have no idea who they are. But as soon as they start doing stuff - as soon as they start engaging with us - we start to get an understanding of who they are, if you know what I mean, in terms of their pattern of behavior.

Again, back to the idea that we discussed earlier - segmentation. What group of similar patterns of engagement would we lump this person into, based on the information we have, so far?

The other idea that I would throw out there is 'retroactive identification.' When an individual comes to a website, they allow a cookie to be placed on their machine. Let's say they engage with us over a period of a few weeks or months. Then they decide to register. And then they decide to sign up.

One of the things from a technology standpoint as well as from an analytics standpoint that we do that may seem simple and straightforward, but you'd be surprised at how many don't think this way and don't do this. We can connect that previously anonymous activity to this known person now.

MM: All that unknown data. Yes.

TC: And all their previously unknown data.

Here's a brand new registrant - but now we actually do have longitudinal data on them. MM: In fact, that would also give you a whole set of metrics or insights in terms of how many clicks - how many particular content-consumption cycles occurred by type or class that it took to get somebody at the register.

TC: Absolutely.

MM: Does Targetbase pull any data in terms of these inferred-unknown people or users from ad networks?

TC: Yes. We've certainly used that. Depending on the circumstance and the client need.

You get into the whole idea of behavioral targeting. It's a very viable approach to targeting.

One of the criticisms that I have of the standard behavioral targeting approach is it's such a limited view of an individual's online behavior. Even with really large network properties online, you're getting a potentially very skewed view into an individual's behavior but it can still be powerful from an ad standpoint, depending on your objectives.

To answer your question, we have - in a couple of instances - mapped in some of that data, where it made sense for our clients on a particular ad network or property that would gain additional insight into the consumers on the database, in terms of their online behavior.

However, that is more the exception. Simply because when we're looking at that, we typically lean more toward matched panel data. We've used Nielsen Net Ratings, 
for example, or we've conducted primary research, where it made sense.

MM: I'd like to share one scenario that I ran across a while ago.

A large car company was spending a tremendous amount of money creating these immersive, virtual-reality movies of their high-end sports car.

TC: Right.

MM: It was clear from the site traffic that it was a very popular feature. Yet most of their preliminary research indicated that some 60 or 70 per cent of the usage tracked 14 -year old boys.

The CMO said, 'Hey. I'm all for branding the next generation and our share-determining market sector. But at the end of the day, I've got cars to move this month. So I really need help in correlating investments in not just these expensive immersive multimedia movies and other sorts of rich Internet applications. But across the 4000 or 5000 pages of content that I have on my site, which of those pages do 45-year olds with household incomes of greater than US\$120000 consume? And why?

In this particular case, the engagement agency went to - I think - the aggregator of DMV records.

They then went to a credit database provider. In this case, I think it was Experian - although it could've been any of the other credit-scoring data providers. They were able to extract or develop a database of all the households that had - in the last seven years - bought or leased a Lexus, Cadillac, BMW, Porsche, Audi a Lincoln, an Infinity and I think there were a couple more brands in there.

They then put that into a high-performance database, underlying the website. When people came to this particular auto site, they basically had to put in their name and zip code. They were able to infer with a fairly high level of confidence that Michael Moon does in fact live in Oakland California, and drives a Lexus GS 350. They were therefore able to track my consumption of media, and able to identify the 1100 or so pages of content and/or media objects that - in this case - a 55-year old who makes more than $\$ 225000$ a year - what pages of content I actually consume.

Do you see practices like that in place today? If not, why not? If so, how has it evolved beyond that basic model that I've outlined?

TC: Actually, in terms of my experience I think that's probably a little ahead of the curve for most companies. I think frankly, just the fact that they're even thinking individual consumer-level identifiable online engagement is a bit unusual.

However, having said that, that's clearly the direction that we believe you have to go.

I mentioned we have automotive experience. One of the areas that we've really - I think advanced their direct efforts - their relationship efforts - has been in the predictive modeling area.

Again, I think that example you give is probably advanced, relative to most people. But if I were going to criticize or recommend some additional layers, it probably would be more in the targeting and the right-to-win area. Again, we've had great success with that in the automotive area.

Maybe it's not a fair assumption that if it's a major auto manufacturer, they'd have records or a database - a consumer database - that identifies their current or previous customers.

A lot of what we've done for our clients has been compiling - not just, as you mentioned data from available third-party sources, but also connecting that to their known customers. Those on their database that have bought cars in the past.

Identifying the ones that are likely, from a predictive modeling standpoint, in-market for a vehicle - or will soon be in market for a vehicle.

Then, which particular car model best fits that consumer's needs.

When it comes to real-time engagement, sorting or ordering the content or the information that the consumer will be able to engage with - based on what they're most likely to be interested in.

That's really, if I were going to be picky, the additional piece I would add to the approach. Targetbase is a little bit different, in that we focus on the consumer - the who - in order to identify those that are top prospects. Identifying those that you have a right to win with, and then targeting them specifically with custom content, etc.

MM: We've found in large, well-established brand-marketing organizations - specifically, 
where they have transaction data - that the CRM system is rudimentary in terms of its data model and its data collection.

TC: Absolutely. I totally agree with that.

MM: One of the most interesting things I've found is that they almost make no distinction between the customer, the buyer and the stakeholder. The customer, in a consumer context, is the household. The buyer is the person who actually paid the bill. The stakeholder might be the consumer that influences the buyer - but is not necessarily part of the transaction record.

In parallel, we have a similar thing with respect to $\mathrm{B} 2 \mathrm{~B}$ interactions. I had a conversation with a fellow who used to work at Compaq.

He said, 'You know, Compaq has almost no idea who their customers are.' All they had was a PO with the buyer's name, and 100 boxes went there. Then over at Digital Equipment because they were a service firm where they made most of their money from professional services - they not only knew all of the departmental managers and admins, but they knew the birthdays and anniversaries and favorite foods.

TC: Yes.

MM: Can you speak to the notion of first of all getting the customer master, and how use a customer master to support deeper, more meaningful insight about when, where and how to engage consuming cohorts?

TC: Well, like you say, that's a very sticky and difficult question. I would say that in terms of knowing your customer, what you describe is very common. We are oftentimes - whether it's a new business pitch or a new client or what have you - we're coming to the table because somebody in the organization ... probably somebody who just came in from outside ... is realizing, 'Wow. We don't even know who our customer is.'

That's why I mentioned before that we often begin with something like a segmentation approach. A segmentation project. So we can help that client just understand even in broad segmented terms who their customer is.

Again, from a heritage standpoint, Targetbase certainly began there, and continues to live there. In terms of identifying who your customers are, what they want from a content and a product standpoint - how they want to be interacted with from a channel standpoint, and then also when. When do you want to engage them? The who, what, when, where, how and why types of questions. That's kind of where we live.

I do think, though, one of the big challenges is when clients do have an existing database that in many cases they've spent a lot of money on, and the data model itself and the data capture is really lacking. Many times, unfortunately, it lives off by itself in the IT department. Marketing knows it's out there. They know that they've paid for it or helped to get it funded. But in terms of day-to-day usage and understanding of the consumer, there's less than you'd hope.

I think, though, in terms of how we try to overcome that barrier - and I could speak at least broadly, in terms of our approach ... back to that foundational principle of ever-improving approximation. You always have to start with what you do know, from a database standpoint. Maybe I've only got a buyer's name and address in my database. But there are things that you can do.

For example, similar to the segmentation process, in terms of appended data at the household level. Syndicated data. Trying to map a consumer's database into a richer data source.

When I say, 'Map,' a lot of that again is where I think Targetbase has really broken some ground analytically - in being able to statistically model and identify key variables and key data points that do exist in a consumer database - that also exist in a richer source like a syndicated data source.

Then with a great deal of accuracy, being able to map individuals over. So we can then infer or at least guess what an individual's attitudes might be - etc.

MM: If I understand you right, Trae - the first order of business is to develop some segmentation insights, and that entails building or acquiring a clean, enriched database of households or businesses.

TC: Right.

MM: Then using that as one version of the customer truth - or one version of the market truth, anyway.

TC: Yes.

MM: Then mapping all of this irregular although real - data from our existing data sources to this customer master. 
TC: Exactly.

MM: Then as a function of that, once we've established the notion of a customer, a buyer and a stakeholder that's part of that overall buying organization, then we can start to lay in additional sets of data - web analytics or e-mail messaging analytics and so on - so as to make that overall customer profile clearer and clearer.

Before we get into the e-mail messaging and personalized messaging, I'd like you to talk to us a little bit about the notion of multi-channel marketing analytics. Specifically speak to some of the web analytics that are now coming into this overall customer insight.

TC: Again, as you know, that's where I think just philosophically, we align so well with Alterian. One of the things that we're so excited about in terms of the technology that they're developing is that alignment.

I think that - back to this idea of tracking consumer engagement, and in a social context everybody knows and has known forever now that word-of-mouth is real. Consumers are talking about your brand. That has always been the case and marketers have known that.

But how, historically, could you leverage that or were you even aware of that? It was very, very spotty - at best. So much so that traditional word-of-mouth efforts have been very limited in scope, typically. Their measurability is highly questionable.

But the exciting thing about social, for example, is that now that's happening increasingly online. It's happening in a context where it can be... Depending on the exact execution, understood - listened to - tracked even influenced, in some cases.

Back to that philosophy of data-agnosticism. Not just purchased data - third-party data but channel data as well. In the sense of, 'How can they help us understand the consumer better?'.

MM: For example, in this last election, it was clear that citizens under the age of 30 would play a pretty significant role in the electoral outcome.

TC: Right.

MM: All of the polling organizations - Gallup, Harris and so on ... They all said, 'Well, these guys don't have phones! They all have mobile phones, and we can't call them!'
It turned out - at least according to the stories that I read - that Fox/Wall Street Journal/MySpace had the most accurate polling data, as a function of all of the hypersegmentation or micro-segmentation they did on MySpace. They were able to - as a function of their engagement with that youth market were able to get very, very accurate polling data in terms of who was going to vote. And of the people that were going to vote, the probability of them voting, and for whom.

TC: Absolutely. Yes. That's a great example.

One of the actual products that was developed at Targetbase many years ago is a thing we refer to internally as 'Channel Selector.' Let's say it's an individual on a client's consumer database. We actually have a proprietary approach to identifying, modeling the channels that that particular individual consumes.

At a pretty detailed level, for television, magazine, online, etc.

MM: Traditionally, segmentation has really driven media-mix optimization.

Now with the advent of the web, social, e-commerce and things like that - you've introduced a new segmentation principle, which you could call 'Channel Optimization.' TC: Right.

MM: That's not just, 'How do we reach out and touch people,' but, 'How do we interact and ultimately sell or engage in a buying process with people?'

TC: That's right. That's exactly the approach we've taken. Identifying the best way to reach an individual, yes. But also tracking the engagement/relationship all the way through.

As a marketer, it's very difficult for me to track all the way down to the final impact of every dollar that I spend in mass media. At least in theory, with more direct methods and that includes certainly online and off you can do that.

So, a lot of what we do for our clients is around that idea of identifying - first of all 'Where are we most likely to reach a particular target from a channel standpoint?' That's the predictive aspect.

Then, to develop a robust test and control scenario. A test matrix where we can go out and prove it. It's not just the high-level bucket of online. No, in fact - for this particular target, what if we put display media out there - versus 
a sizable presence on Facebook - versus pushing a mobile application? Which of those drives individuals to actually purchase the product, and then what's the ROI for that particular micro-channel?

It's a combination of prediction and testing. Because the data sources - at least in my experience - often aren't granular enough to rely on modeling and prediction alone.

Not to get off-topic, but I think that applications or widgets are the real thing to look out for, from a marketer's perspective, in the future. Because the web is becoming a programmable platform on which individuals can program and dictate what they see or don't see in a marketer's message - etc - it's increasingly necessary to have the scientific rigor behind your marketing programs, so you can improve that. 'This combination of content and placement and target drives the highest return.'

It's really taking media-mix optimization many levels deeper. It's more about the marketing mix optimization all the way down to - like I say - perhaps a very fine grain.

MM: One of the things I'd like you to speak to, Trae, is the notion of search analytics.

Many companies have volumes and volumes of search terms and arguments used on their websites. Unfortunately, a great many of those terms really don't bring satisfying results.

TC: Right.

MM: How have you seen forward-looking innovators start to use those search terms, search frequency and derivations in providing some additional insights? In terms of who's wanting what, and how we're not fulfilling what they want?

TC: I have two distinct thoughts on that. The first is, there are really innovative thinkers in the area of search. They're starting to realize that when you're thinking of consumer analytics, targeted search is where the real return is.

For example, it may be that putting a particular word out there - or buying a word, let's say ...

MM: I want to draw the distinction between buying ad words and search terms as linguistic artifacts that reflect a particular ontology of desire - awareness, consideration, trial, commitment, loyalty and advocacy.
I surmise that we'd find a treasure trove of actual search terms that somebody used at a large site - the actual words that were put into the search box. It seems to me that there's both an ontology and taxonomy of desire which very few companies analyze, much less apply in any kind of useful way.

TC: I'm really glad you brought that up. We do host, develop and certainly analyze and report on many web properties for our clients. One of the things that I, personally - as well as many others in the organization - really harp on is the need for internal search.

To your earlier comment about the voice of the customer - you get no more direct voice of the customer than someone typing in, 'Here's what I want you to give me from your site.'

We've had some success in that area - and sometimes not so much, in terms of getting our clients to understand just how valuable that is. So there's internal and external, obviously.

One of the things we do for a few of our clients is - and this sounds very fundamental, but again, I don't know of many others who are doing this.... When an individual finds your website - let's say they're coming from outside. They type in a term on Google, and they're driven to your website, as a result.

If you know what you're doing - from a technology standpoint - you can easily track the term with which they entered your site and what drove them there.

However, I don't know of very many that are using or storing that term in a database. So if I know this is John Smith or that it's Cookie 1234, regardless of how I choose to identify that visitor, I can store the term that brought them there.

You can use that analytically in many ways. For example, people that come to my site searching for 'Term $\mathrm{X}$ ' tend to exhibit the following pattern of behavior. So when somebody comes to my site in the future, using that same term, I'm going to then dynamically serve up content that I know they're most likely going to want to see. So I can use it for prediction in that way.

Then of course there's internal onsite search, which I think is just as, if not more, important depending on the particular client. When somebody's on your site and you allow them search functionality - and they say, 'I'm looking 
for product A or product Z,' or, 'I want information about this,' obviously, in a very practical and functional way, that's what you're going to serve up.

But then you should store what they've searched for. So let's use a hypothetical example. If somebody comes to your site and they always search for products in a particular category, shoes, let's say. If that person's opted into a newsletter, then guess what content should be at the top of their newsletter? It should be 'shoes.' Increase the relevance based on what that consumer has searched for in the past.

That's a rudimentary example, but, again, not too many in my experience are utilizing that very valuable information.

It all comes from and starts with a data model, a data approach that says, 'I'm going to appropriately store and capture what an individual tells me they want.'

Then from a campaign standpoint - and I use that term loosely, it could be dynamic web content. It could be a mobile campaign. It could be outbound, etc. I'm going to be able to leverage what they told me they want from a content standpoint. And, I will test, learn and optimize my way into a much more meaningful, relevant communication.

So I can learn if - in fact - this is causing an increase in engagement or if it's causing an increase in purchase.

MM: This reminds me, Trae, of a conversation in a workshop I helped facilitate over in Finland. In particular, it was a large power company. We discussed their strategies for jumpstarting a full-spectrum engagement program that would eventually move millions of consumer and business customers to online bill presentment and payment.

Our discussions came to the inevitable, where to start? We hit upon, and ultimately they've begun executing, something I call a 'voice-of-the-customer content analysis.' TC: Yes.

MM: In principle, it's something that professional marketers have done for decades. Ever sine they had long-distance telephones that came into North America - I guess in the 1950 s.

It entails interviewing a set number of customers per month, in a 20-to-30 min session, asking, 'What was going on in your life? Why did you choose this? What influenced your selection of this brand or that brand? Tell me a little bit about your life - the applications of use. Who really has said what about it?' And in a B2B context, 'Tell me a little bit about your business. What was going on? What catalytic event induced you to take action? What criteria did you use in determining that you had a problem worth spending money on solving?'.

TC: Right.

MM: Verbatim transcripts of these interviews go into a specialized content database that a content modeling specialist then text-mines, semantically tagging keywords and phrases, using a faceted taxonomy with growing vocabularies, associations and logic inferences.

In the beginning of the text mining process, you tag the easy ones: names of people, companies, products, places and so on. With hard work you then start to expand various facets of a multi-faceted taxonomy; each facet represents a logical set of naming terms within a context, such as all the types of geographic locations - village, town, borough, county, etc. With additional work, you begin creating topic maps, such as politics or technology, building a thesaurus of all terms, concepts and synonyms associated with a particular topic. With a topic you start making semantic inferences in terms of things like 'concepts, time periods, pain points' and so on.

TC: Right.

MM: Over the course of several months, you can then start summarizing the voices of customers at various stages of their journey in a dashboard, tracking shifts in awareness, sentiment (pro and con) and use cases. Thus, using specific keywords and phrases that customers uses at various stages of engagement, content analysis of the voice of the customer provides a stunning new set of insights, that one can and should drive content creation, meta-tagging of content for search engines, search quality assurance of a site, and management of a dynamic inventory of what keywords to buy.

TC: Yes. In fact, we've done similar things from a consumer-sentiment-tracking standpoint for a few of our clients. We heavily emphasize the need to incorporate 'voice of the customer.' 
Targetbase is the consumer's advocate, on behalf of our clients.

But one of the truly innovative ways that we're approaching that now - and this is very recent - is through the use of social listening. Leveraging partners such as Umbria or BuzzMetrics.

MM: They have spiders that crawl through blogs, forums and social networks.

TC: Yes. That's right. They scrape that information and store it. Interestingly, not only do they store it - they also think as best they can, longitudinally about those who are active - in terms of commenting and making posts online, etc. They store the information longitudinally.

They do a pretty good job of gleaning insight and segmenting the voices they hear, out there.

As you know, when you go out and interview a consumer, it's possible that just by virtue of the fact ... well, it's kind of like Heisenberg's uncertainty principle or the observer effect for market research. You can't accurately measure because...

MM: Well, the measurement perturbates the field of observation and alters the thing one wants to observe.

TC: Yes. Thank you. Yes. Exactly.

When you go out and actively poll or ask your consumers, you might be missing something or skewing the results. The interesting thing that we're working with Umbria on now is how we partner that approach with the listening approach. Granted, there are some skews due to scale, depending upon your use or if you're objective is in question.

But we're finding some really interesting ways to marry up the direct questioning or polling of consumers with just sitting back and listening.

One of the areas that we're actually partnering with Umbria on is two-way segment mapping. They have their tribes, and we have our consumer segments that we develop for our clients. We're working toward mapping in some cases - the robust segmentation we develop for our clients onto those to whom Umbria listens.

And then coming the other way - when they've developed a robust and interesting attitudinal tribal segmentation, mapping that onto a consumer database. The intersection, of those two - what we know from an attitudinal, psychographic, geographic, standpoint and what they know from a 'buzz' standpoint oftentimes leads to some really deep insights. In terms of the taxonomy not only of content, but just of the entire consumer relationship.

So, how do they perceive the category? How do they perceive our brand versus competitors? What 'voice' should we use when we're talking to a particular segment or sub-segment?

We're identifying ways that we can customize content, in terms of outbound communications, specifically, that allow us to see an increase in engagement. So we're now talking in terms that the consumer understands - the way that they feel - they way they talk about our products and services.

As a result, they're engaging more. Right? Deepening that relationship.

MM: Trae, in many respects, if you boil it down or get it down to its most essential element, all you've got are data and keywords or phrases.

Then when you bring them together - data about the keywords and phrases - you've got in many respects an engagement object.

TC: Yes.

MM: These engagement objects really almost work like brain receptors. They're waiting for a particular ion to come by and activate its ion channel. Right?

TC: That's right. Yes.

MM: So the notion that at the foundation of an engagement cycle is essentially this engagement object.

You've got a keyword or phrase. And you've got metadata describing the relevance of that particular idea, keyword or phrase to a particular profile of consumption.

TC: Yes. Absolutely.

MM: I want to throw out another aspect, before we actually get into the content-creation and messaging piece.

It's this last piece around guerilla marketing and viral videos.

One of the companies that I've interviewed is over in the Netherlands. It's called LaComunidad. They're part of a WPP family of agencies.

They had a sports shoe company come to them, who had a hard-court sports shoe 
for handball and racquetball. They went to LaComunidad and said, "We think that a social marketing program really makes sense. Can you identify the 10000 fanboys with blog sites (or as I call them C-captains as in community captains) that hold forth in various social networks like Facebook? Can you identify the 10000 or so fanboys that speak about sports shoes in general? And specifically, hard-court sports?'

The team came back a couple of weeks later and said, 'Here's a spreadsheet with the 10000 or so fanboys across Europe, Middle East and Africa.'

TC: Right.

MM: Then the sports shoe company said, 'Okay. What can you do with that?'

Igor came back and said, 'Well, we suggest that we identify the 1000 of the 10000 - the top 10 per cent of those fanboys - that are explicitly for your brand, or that are inclinable. In terms of that they're not affiliated with your competitors. They seem to be not really affiliated one way or the other, but might be. TC: Right.

MM: Then Igor and Team went to those 1000 fanboys and said, 'Here's some unpublished video content that we think you might find interesting. Would you like to look at it? And, if you opt into it, would you post it at your site?' So by opting in, LaComunidad certifies each fanboy as potential advocate, capturing the name, contact information, some demographic and lifestytle items as well as content profiles about each fanboy's blog, site traffic and such.

In addition to that, they say, 'Okay. If you agree that this is cool stuff, we'll pay you to publish this at your site. And we'll pay you per-click in terms of people that click through the video back to the sports-shoes company's micro-site.'

That became what he calls, 'Paid seeding.' TC: Yes.

MM: The net result is, they ran this program for several months. I think the total spend on it was about $€ 200000$ or 300000 .

TC: Right.

MM: But when they looked at the data, in terms of reach and impressions and dwell-time, interaction with the brand - the data basically made the case that to have had this level of consumer activation of boys aged 14 to 28 the shoe company would need a $€ \$ 10$ million conventional ad-spend to essentially achieve the same result as this €200-300000 guerilla viral-video spend.

TC: Yes. That's a great case. That's consistent with some cases of clients that we've worked with.

My first comment is that I love the contentseeding approach. I'm sure you've witnessed this, too, that viral video is such a buzzword and such a hot topic over the last couple of years - or at least since YouTube has been around.

So many times we get clients coming to us and saying, 'I want a viral video. Make me a viral video.' Or, 'I want a viral marketing plan.' That's my personal favorite - an oxymoron, I think.

But our response to that is always, 'Okay. Great. But let us help you establish a contentseeding strategy that can really get the word out. Or at least increase the chances of you getting the word out.'

For example, one of our CPG clients had an altruistic program that they were working on. One of their scientists came up with a way to very quickly purify massive amounts of drinking water. Just during the R\&D process, he came up with this.

They decided to distribute these things these pills, basically. You drop them in a bucket and stir it around and it purifies the water to make it drinkable. They wanted to distribute them in poor countries. They wanted to from a PR standpoint, as well as a consumeractivation standpoint - get the word out.

They wanted people to know, 'Here's what we've done, and here's how it works, and here's how you can help.'

That was one of those examples where we used the seeding approach. Not in terms of the scale, because it certainly wasn't $10000-$ but identifying activists - online sites that were trafficked - blogs that were trafficked individuals that were verbal and outspoken when it came to those types of issues, to post and identify who we thought would likely be a powerful influencer. In this case, I think we actually posted video. There was a micro-site involved that then publicized the content. It pushed it out to a sector of individuals, much like you're describing. 
One side comment - a danger that we've witnessed in this area is if you go the route - as they did in that example - of actually identifying fanboys and then paying them to speak positively about your brand, the Internet community particularly younger users online - has an uncanny ability to sniff that out. And that can backfire.

MM: In fact, Igor and Team have addressed that - I think, successfully. By going to the fanboys and saying, 'Look. Do not commingle our content with your content. Rather put it off to the side as a paid spot.'

So it's clearly indicated, 'Brought to you by the big sports-shoe company.' And then have the fanboy explain, 'Hey. By the way, this is how I pay the bills.'

TC: Yes. That's smart. That's a good way to handle it. Just to avoid the issue.

MM: You're absolutely right. The net citizens have a seventh sense in terms of manipulation, coercion, lack of authenticity and ulterior motive. TC: Right.

I think it is a really interesting problem, in terms of the content. You mentioned early on the whole notion of user-generated content versus more corporate-produced content.

I think we've had some good luck on both sides. The key is certainly transparency. But also, it's the targeting. That's what's so interesting about the case that you cited, the rigor that they put into identifying where this should be seeded.

I think that a big mistake that a lot of our clients have made before they came to us, and others that we see making is this idea that if you just create great content and put it out there, people will come. It's counter to or at least is the exception to the rule. It's more a big-seeding approach. That sounds like exactly what those guys did.

MM: They talked about both organic seeding - which is you put it up onto these various video-sharing sites. You tag it in a manner that a member of that cohort would tag it. Then you kind of a do a friend-to-friend, 'Hey - did you see this?' But it tends to be organic and passive. Oftentimes it takes weeks or months for it to catch on.

TC: Actually, I have a good example that we're right in the middle of, now. One of our clients is an arts-and-crafts retailer.
One of the things that we're doing for them now is very social, viral in nature. They have a celebrity personality who's their expert crafter. For the holidays, one of the things that we developed for them was a social communications strategy.

Basically, we built a micro-site where the expert crafter is the feature. She's doing crafts with basic materials you can buy at the retailer's stores that turn out looking fantastic and are really easy to do. etc.

From a marketing standpoint, one of the ways that we enriched that program as opposed to the more old-school way of just going out and building a micro-site and then e-mailing all your customers that it's there ... In this case, we created - as well - a Facebook page for not only the site, but also for the expert crafter.

This drove consumers - existing customers not only to the site, but to the Facebook page that the video was posted on. All the videos actually are posted on YouTube, with the appropriate tagging, etc - to allow people to find and share it.

Those efforts resulted in huge traffic and engagement. In fact, for the month of November, one of the retailer's videos was recognized by YouTube as the highest-viewed video in their category. Over 900000 views for that particular craft video.

It was a tremendous success. I didn't think that many people on the planet were interested in crafts or wreaths. But apparently they are. It was only by wrapping that content in the social context - promoting it maybe initially with your current customers ... But also, reaching out to friends of your customers via Facebook, and seeding the content in a place like YouTube, with the appropriate searchable metadata, etc, in order to really see it take off. MM: I think what you're now beginning to bring forward to our conversation emphasizes a content strategy.

To summarize what you said - first of all, micro-sites are now not just a standalone kind of 'go to it, have your experience and go away,' but it's part of a larger social-media web. TC: Absolutely.

In fact, people laugh at me because I say it so often here internally at Targetbase. The 'site' is dying. By that, I mean that the 'site as destination' is fading. Consumers can - 
increasingly - and will continue to engage with your content where and how they want to. Or they won't. So if you don't have your content accessible and reachable via mobile, via social, etc - depending on the target of course, and being smart about it - then you're not going to be able to optimize your marketing effort.

I believe it was MarketingSherpa a while back that did some research and identified that the average person has - at least from a destination or site standpoint - a top 12 . They engage with those almost all the time, online.

The old-school approach is, 'How do we break into the top 12?' What we're suggesting at Targetbase is, 'No, no. You don't necessarily want to break your site into the top 12 .

You want to perhaps, using Facebook as an example, put your content into the context of a top-12 site.'

MM: Right.

TC: It's just like social ladder-climbing, in terms of interpersonal relationships. If I want to get to know the mayor, just walking up to him or trying to storm into his office isn't going to work. But if I have a friend that's friends with his daughter, and I work that angle, then eventually, I may get to know the mayor.

It's the same idea of how you put your content into the appropriate context - for your target - so that they're going to consume it the way they want to consume it. It may need to be a Facebook application.

Back to the old branded food site example ... I want a recipe of the day, but I don't want to come to your website every day to see it.

MM: I'm already going to one of these 12 on a regular basis.

TC: Exactly. So, make it portable. Put it where I am. Don't make me come to you.

MM: I use the metaphor of a 'brand engagement theater,' in particular, to really bring forward and highlight several themes of engagement.

Engagement happens tribally. Tribes, by definition, create a social context.

The notion of a theater basically brings forward that, 'every brand tells a story.' A story about what it means to be in a relationship with the brand. But it's a story that evolves through various phases, allowing us to use all of the cultural narratives of how we tell stories.
It takes back to Aristotelian poetics and classic form of a 3-act play with each act having a setup, build and payoff - all of the traditional classic models of how you tell a story.

TC: Right.

MM: A brand-engagement theater also highlights the notion that we need to tell a story to someone and, with success, we can pierce that fourth wall - between the audience and the theatre.

Not only to pull them into the narrative as an observer, but actually as a collaborator. Ultimately, we're trying to get consumers to engage in the brand as a theatrical experience that kind of sweeps me up into a narrative and takes me someplace.

TC: That's right. That's again back to the Alterian technology side of things. Ideally, that story should develop in reaction to the consumer's engagement.

When I was a kid, we used to buy these books where you choose the story. You'd get to a certain point in the story and it would say, 'Do you want to go left or do you want to go right?'

You're changing the story by engaging with it, in terms of dynamic content and in terms of customized content - beyond personalization. Don't just know my name. Serve me the content that I want to interact with, in the way I want to interact with it. Then when I do interact with it, recognize that and change how you treat me in the future.

MM: Trae, that really brings forward another controversy: personalization. I think that many people find some level of non-collaborative personalization off-putting but scary; you know, we I encounter a company that know more about me that I shared with them, it's just weird. Like what else do you know?

TC: Yes.

MM: So there's the notion of personalization, which inevitably becomes kind of creepy. There's this other notion of individualization where now I'm kind of configuring things to serve my needs.

TC: Wow. That's incredible that you're going in that direction. I was just recently having a conversation with a client on this topic.

Everybody's familiar, at least in a limited sense, with the idea of a 'preference center.' MM: Right. 
TC: I can go in, and tell you to some limited degree from an operational standpoint - how I want to interact with the company. But we do a really poor job of porting that approach over into the area of marketing. 'Let me tell you.' I'm a consumer. 'Let me tell you, company, how I want you to engage with me.'

So I think you're absolutely right. At least that's what we believe. You want to avoid the personalization 'creepy' factor, and actually be forthright. To say, 'No, no. We're letting you dictate our engagement.'

MM: That gets to an underlying sense of what Lawrence Lessig of Stanford calls, 'The remix culture.'

I also want to bring up this notion of a consensual database. About 15 years ago in a Direct Magazine or Catalog Age, I read a fascinating article that came out of IBM around this notion of 'consensual database marketing.'

Of the many things their customers complained about was the inundation of IBM customers with direct mail. EDP and IS managers would get four and five direct-mail pieces a day from IBM. Worse still, 80 per cent of these mailers related systems long retired and thus no longer relevant.

The poor account executive found that there were some 70 or 80 databases within IBM that were mailing this stuff into this poor IS manager's office.

So they ceased all mailings to all of our customers. And they then created a consensual database in terms of what customers wanted to hear about.

TC: Exactly.

MM: In my book, 'Firebrands,' I expanded that into what I call 'information preferenda.'

Now, 'preferenda,' is a term from biology. It relates to all the stuff that attracts the attention of a motile organism. Thus, sunlight and water constitute preferenda of a plant.

Information preferenda describes all the classes of information by media type and manner of fulfillment that a knowledge worker would want to consume.

TC: Yes.

MM: Back to IBM and their consensual marketing database. They requalified their entire customer base, defining what each customer wants to hear from IBM and explicitly what areas each customer does not want to receive communications or mailers.

The net result, IBM realized an $\$ 87$ million cost-savings in the first year.

TC: Wow.

MM: They sold four times as much on a drastically reduced mailing schedule.

Your idea of a preference center really syncs up nicely with IBM's consensual marketing data and my notice knowledge worker preferenda.

You know, it's not just, 'What products do you want to hear about?'. But, 'What categories do you want to hear about?'. That leaves open the door to engage the customer in the future when we have a real offering in that category. TC: Yes. That's right.

Again, from a marketing standpoint, 'What channels do you want to be communicating on? Do you want e-mail? Do you want it just on your mobile? Do you want to come to us? Do you want us to come to you?'

Allow them a greater degree of control. The consumer is now predisposed and expecting that level of control.

If you look at any channel these days pretty much ... Take TV and TiVo, for example ... MM: Right.

TC: I can shift time. I can skip your commercials. I choose what I want to do.

The consumer is becoming accustomed to that. So much so now, I would argue, that as you said before, 'If you don't offer that, then I don't need you.'

Frankly, if you don't offer that, before long ... back to my earlier comment about the 'programmable web,' there will probably be someone that will 'hack' your content such that I can actually control what I get and don't get, anyway.

If you look at - for example - iGoogle, MyYahoo - in fact, my personal preference is a site called NetVibes. If you're familiar with it.

The idea is that it's simply a platform for widgets and feeds. I can control what I see and what I don't see. I get to control the content on that page.

Back to the whole Top 12 idea - that's my Top 1. I don't go many other places. At least if I do, it's from a jumping-off point of NetVibes. So I'm controlling it. Again, I'm sure you're familiar with Firefox. The browser. 
One of the things I love about it is the plug-ins. The add-ins. One of them is called GreaseMonkey. Granted, it's a little geekier than most users are comfortable with - but GreaseMonkey allows you to edit JavaScript. There are others, of course, who've made their own edits. You can easily download and install them yourself.

I can choose to see your ads or to not see your ads. I can choose to take two totally different pages. I can take a competitor's page and your page and smash them together on a single page. I can do whatever I want to do with your content.

The point is - and I kind of hinted at this earlier ... As marketers, we'd better wake up to that fact. Or we're going to be left out in the cold. The consumer is in control.

I think some of that is an emerging trend. But, there are definitely aspects of it that've been around for quite a while.

MM: As William Gibson, the great Cyberpunk author, said brilliantly, 'The future arrives unevenly distributed.'

TC: Exactly.

I think that for some marketers - unless they're alerted sooner - it's going to come as a big shock that, 'Oh, crap! My online media isn't doing anything for me.' Why isn't it? Well, because it's easy to ignore. It's easy to block. It's easy to mash up.

That's the point.

Back to the site dying. If you expect your site to be one of their top-12 destinations, good luck! For some lucky few, that's going to be the case. But you've got to realize that there are going to be an increasing number of consumers mashing up content and deciding what and how much and when, etc, they consume it. So much so that if you don't start to approach it from that 'preference center' mindset, they're going to ignore you. Or they'll choose to consume it however they want to, anyway.

MM: Let's explore the notion of marketing operations. We'll start with a few presuppositions.

I think many marketing professionals can agree that marketing no longer entails just developing insights, messages and program putting lipstick on pigs. Increasingly, marketing now entails the development of interactive, on-demand, re-mixable customer self-services as well as the provisioning of these services to my customers and potential customers.

TC: Right.

MM: So in many respects, the career path for tomorrow's CMO rides the rail of digital service platforms and IT service provisioning.

It's going to require a completely different mindset. Now, in this interview we spent a lot of time already talking about the 'analytic mindset.'

It starts by working backwards from the customer's preferences and cohort and into the product portfolio mix. Using that, then, to do media-mix optimization in terms of, "Where do I spend my scarce marketing dollars, to activate those consumers and those cohorts that I want to have the right to win?'

Then I begin to see that it's not just winning, but keeping them. How do I keep them? How do I keep them engaged? I have to be able to customerize content and services. TC: That's right.

I would say another piece to that is something you mentioned before. 'How do I or how can I intelligently leverage user-generated content?'

The age-old example of Amazon.com, their recommendations and their ratings. That was a brilliant insight on their part, to realize that, 'I can allow customers to generate content on my site that's not only going to make that customer happy who got to rate it, but it's going to inform the purchase decision of future customers. They're more likely to come here as a result!'

MM: Well, back to this notion of a preference center or information preferenda. I'd like to have another social indexing of 'who said what?'

It's one thing for a 22-year-old college kid living in a dorm to say, 'This is cool.' It's quite another thing for a 55-year-old business owner to say, 'This stuff works!'

So I'd like to be able to cut through a lot of the ratings and ask, 'For people like me, what do they say?'

TC: Exactly.

In fact, it brings to mind an idea that unfortunately - we weren't ever able to execute for one particular client. It was a real estate site.

The idea that they had wasn't necessarily a bad one. It was, 'Can we create neighborhoodlevel sites, where as a neighborhood - as neighbors - people can exchange information 
and recommend restaurants in the area, etc?

To share information about the neighborhood.'

The business model idea they had was that

the thing would be funded by local advertisers. Local restaurants, local service providers, etc would be interested in being there, from an ad perspective, etc. Because those are their local customers.

The idea seems a bit dated now. This was a while ago.

One of the things that we recommended and pushed back to them was the idea of... In terms of both profile and preference center - if an individual comes on and you understand who they are, then you can do a better job of matching them up with other individuals in the neighborhood or in the general area that look like them.

For example - to your point ... If I'm looking at the average rating of a local Thai restaurant, then I can filter - if I want to down to people who look more like me. So, people who like stuff that I like. Or people who .... whatever the parameter is you want to choose. Those who are like me. What do they say about this restaurant?

MM: This gets to the concept of content optimization. And how content optimization really leverages or exploits three sets of metadata.

There's a set of metadata around the customer. You could call that a 'customer object.' Right? TC: Yes.

MM: In that customer object is all this basic demographic and psychographic stuff. Plus, there's a whole bunch of preference metadata, as well as my media-consumption profile. What you called your 'patterns of engagement.' TC: Right.

MM: That would all be part of my customer object.

Then I've got a content object. Around that content, I've got a smaller schema of metadata in terms of the meaning of this - the social context of it. Where it tends to get highly rated or highly used. What search arguments it tends to satisfy. What search arguments it doesn't tend to satisfy - etc, etc.

Then I've got a set of metadata around my ad inventory.

Also, what I have on my ad inventory is, 'What kind of context does this ad have a particularly high lift and/or pull lift?' Are there keywords and phrases that are part of the topic map by which this thing got tagged?

Are there particular keywords and phrases that it tend to activate or lift well on, as opposed to not well on?

The convergence of these three sets of metadata - the customer metadata, the ad inventory metadata and the content metadata really allows me to then create highly activated or potentiated contexts for consumption.

TC: Yes. That's right.

MM: The idea is then that part of my content optimization ... Inevitably, going back to what I introduced earlier in terms of our voice-ofcustomer content analytics. It's taking that same technology - text-mining, semantic tagging and so on. Starting to hypertag my content in terms that allow me to create faceted search, dynamic navigation and personal tag clouds.

So when I show up with this customer data model, it activates these particular content tags TC: That's right. Exactly. Yes.

MM: How do companies start doing that? TC: There's a technology component. What you've just described is a pretty wicked mashup of tables and fields, from a technology person's perspective. How do you associate properly all those different data points? Or at least those three big conceptual areas?

Then, there's the math. The analytics. How do you identify what belongs together? How do you identify the relationship between those different tags and/or data components and customers, etc?

I think that's what's so exciting about this conversation. I think philosophically, we're in total alignment. And, what I love about Alterian - they're there, as well.

I think we're taking steps to that ideal. I think we're moving in that direction. I think the biggest problem we have at Targetbase in terms of our clients is, so many times clients have more fundamental issues than what we're describing. So what we're describing sounds like a pipedream.

I think that the underlying components are really technology and analytics. That's why I truly believe that, whether just by pure dumb luck or by clairvoyant management, Alterian and Targetbase are uniquely positioned to take advantage of these trends that I think we're all seeing. 
MM: Right. Let's use that as a segue into the notion of engagement partners. Specifically, the evolution of the traditional ad agency or digital agency and/or marketing service provider into a real partner that differentiates the value proposition.

First and foremost that entails asserting, 'We are a center of excellence.' Secondly, 'We have mastery of the technology and the analytics.' And thirdly, 'We make our offerings available to our clients for not only a baseline compensation, but there's performance upside.'

Such that when we generate revenue or key performance indicators of revenue - we get compensated for that. Because we're dealing in such transparent, audited processes, basically, you pay for the value that we help create for you.

Could you take us through the evolution or the other way of expanding upon the notion of an engagement partner? And what that really means, in terms of systems, processes, accountabilities of that organization?

TC: As I said before - at least in my experience - I think that is still an emerging thing. I'm not sure that anyone including we at Targetbase have really come through to the other side, in terms of what this is going to look like in the relatively near future.

But I certainly agree - and we've been talking internally at Targetbase for many years - that that's the way we not only should be going, but eventually we will be compelled to go.

The old-school ways of approaching it are not going to be as effective. Let's take it from the client's perspective. The client's not going to get the same bang for their buck if the way they're executing their marketing programs is in a very siloed agency or old-school agency way.

Even when you have agency partners that work well together, it's still not ideal. Frankly, that's I think for some of our longer-standing client relationships, why we've been so successful. Those that have been around the longest tend to lean on us the most for that strategic, analytic partnership. Not so much the execution side of things.

It's because they want that - what I mentioned before - agnosticism. They want that objective third party. Someone they feel they can trust to help guide them through all these decisions.

From the client's perspective, we see at least our greatest client relationships and longest-standing client relationships - that's what they value most. Even when times are tough, they may cut our budget, but they still hang onto us. Because they know when they come through the other side of a tough time, they're going to need that partnership. They're going to want that relationship - that engagement partnership as you call it - to still be there.

But from the Targetbase perspective, I think one of the things that we've recognized in the last few years is the old-school, fee-based model of working with our clients is becoming increasingly challenging.

So much of the revenue under that model is on the production and the execution side. That's not to say that's not important. It certainly is, and we will continue to maintain that and deliver on that in a very best-in-class way. But that's also the most commoditized portion of the business. The production and execution side.

Take, for example, database.

We've recognized now for a few years that the database used to bring a certain level of margin just by virtue of the fact that you were providing a relatively advanced, customized technology.

The understanding of that technology and how to make it work for the client. That is increasingly commoditized.

So much so that - granted, to a lesser degree - you can go online right now and, for free, start your own database.

We and - I think agencies, in general people who provide these services - have to do a really good job of identifying what is a commodity, and price it accordingly. Then the thing that you're describing - the engagement partnership - that's where the real value is.

Then the question becomes, 'Okay. That doesn't require as many man-hours to execute. How do we realize, as an agency, the payoff for work that resulted in millions of incremental dollars for our clients, when in fact, we would've normally charged them $\$ 50000$ for that?'

MM: You're dealing with both a mindset, a business model and - specifically - a valuecapture mechanism. So first of all, let's deal with the mindset.

Really, what we're talking about here is way beyond the agency mindset.

TC: Yes. 
MM: The agency - for the most part - is a service firm. A professional business service firm where it takes on projects or programs, and basically charges for them, based on 'How many expensive powers of my people did we consume?'

As a service business, their resource base tends to be fairly flat. It's basically projectmanagement, communications - the telephone and a database, maybe. Right?

TC: Right.

MM: So there's a certain amount of risk and effort associated with creating an agency. And markets generally reward risk and effort, in terms of a fair - if not intuitively derived margin of profit.

You're talking about a center of excellence an autonomous business unit that uses its working capital to drive investments in new processes that shorten cycle time and reduce costs. That reduces labor from the overall deliverable, and increases quality and increasing effectiveness.

It's a new concept or a new distinction of a business model. First and foremost, you're a digital service factory or a digital services platform. There are certain inputs and you kind of do your stuff, and there are outputs. Those outputs have a more tangible, measurable economic value.

It seems to me that you have to say, 'First of all, we're not an agency. We're a digital services platform. More specifically, we're an engagement platform. If you didn't have our sauce on your steak, your revenue line would look like this, and your future free cash flows would be this.

With our sauce on your steak, your revenue line is 'this,' and you're future free cash flows are 'this.'

So we want to get a percentage of the economic contribution that we bring to you. We've got the analytic rigor by which to create some fairly effective, predictive models.

I'm going to introduce a radical notion of 'revenue and profit per database record.'

TC: Yes.

MM: At the end of the day, that's all. There's no other purpose for a firm than to find and keep a customer.

If you accept the premise, then the institution of a customer is a customer database record.
Now it's a shame that most companies have really ineffectual customer databases, and that they don't know the cost of creating a customer, nor do they have any longitudinal data in terms of what they do with us.

So it seems to me that the first order of business for an engagement partner is to establish a clean customer database. And more specifically, one that allows me to calculate with a fair degree of probability the predicted, long-term revenue for database records.

And the predicted long-term profit of a database record.

That's industrial, factory kind of thinking.

It's unitized work or units of work. Right? TC: Yes.

MM: The first job is, 'Look. You're going to pay us whatever the cost is to create a database record.'

TC: Right.

MM: That then becomes the baseline for measuring the effectiveness of what we do.

Here's the other thing that's kind of interesting that we found in the larger field of digital asset management.

In the database marketing area, direct marketers traditionally capitalize the costs of a customer database.

TC: Right.

MM: It's an asset on the balance sheet.

Admittedly, it's an intangible asset, but it's an asset that has inferred or derived economic value.

So it seems to me that in terms of the engagement partners, the purpose of an engagement partner firm is to make tangible and concrete the value of a database record. And to do it in such a way that you can satisfy GAAP principles.

So as now to make it a formal asset class on the corporate balance sheet.

TC: Right. Totally agree.

MM: That changes the value proposition. Because it drives share price.

Ultimately, engagement really entails quantifying customer database record contributions to share price.

TC: Yes. That's right. Absolutely. That's exactly why, with engagement at the center of that discussion, you have to be able to capture and store and understand and predict the impact that engagement has on your bottom line. 
MM: Right.

What happens is that the ' $\mathrm{C}$ ' in CRM becomes an 'S.' It becomes 'stakeholder relationship management.'

So now, no longer am I interested in just you as a customer, but who you are as an advocate for me in the marketplace.

TC: Right.

MM: Ultimately, as I'm thinking - five or 10 years out - CRM is going to die.

TC: Yes. That's right. In fact, that's another thing that I tout internally. CRM, as traditionally defined, is a dated approach. In fact, I've got something scribbled on my whiteboard now. We were talking earlier today about this.

In addition to the point you're making, the context of consumer relationships is no longer just between you and me as a company and consumer. The relationship is distributed, including a broader context of content, locations and social influence.

MM: I've got this model that I developed elsewhere. It suggests that initially, the relationship is between buyer and seller.
Then it becomes a relationship between customer and vendor, or customer and provider.

Then it evolves, ultimately, a relationship between stakeholder and institutional citizen.

Where now I'm not only a customer I advocate on your behalf - but ultimately I am now part of your overall formation of social capital.

TC: Right. Yes.

MM: Thereby closing the loop on social responsibility and sustainability things. Now I'm actually tracking - as a function of our marketing programs - our contributions to the health and well-being of the stakeholders and our markets that create the foundation for consumers to buy stuff.

TC: Yes. That's right. Absolutely.

MM: We really covered the topic, today. Huh?

TC: It's been really engaging. I've loved it.

I think the philosophy that you're outlining is one that we all - maybe separately or who knows how - have arrived at. It's just a matter of, 'Let's make it happen.'

MM: Fabulous. Again - thank you so much. 